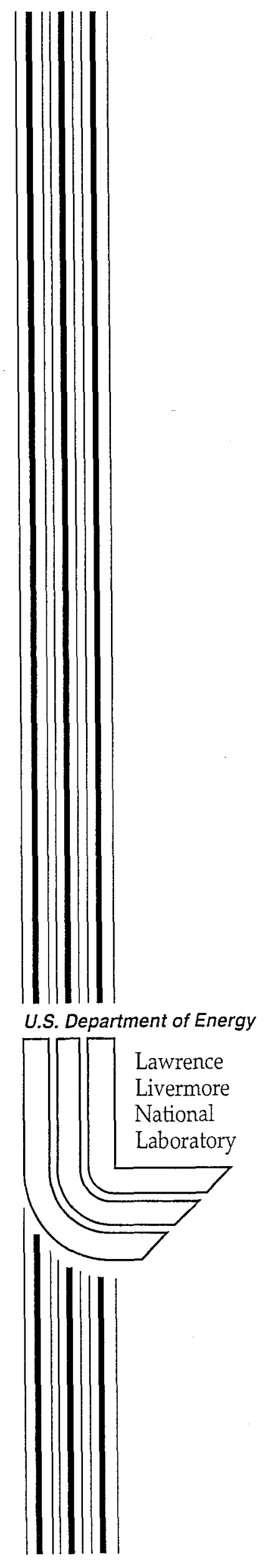

Preprint

UCRL-JC-135092

\title{
Core-Level Satellites and Outer Core- Level Multiplet Splitting in Mn Model Compounds
}

\author{
A.J. Nelson, J.G. Reynolds, J.W. Roos
}

This article was submitted to $46^{\text {th }}$ American Vacuum Society Symposium, Seattle, WA, October 25-29, 1999

\section{October 18, 1999}




\title{
CORE-LEVEL SATELLITES AND OUTER CORE-LEVEL MULTIPLET SPLITTING IN Mn MODEL COMPOUNDS
}

\author{
A. J. Nelson and John G. Reynolds \\ University of California \\ Lawrence Livermore National Laboratory, Livermore, CA 94550 \\ and \\ Joseph W. Roos \\ Ethyl Corporation, Richmond, VA 23217
}

\begin{abstract}
$\underline{\text { Abstract }}$
We report a systematic study of the $\mathrm{Mn} 2 \mathrm{p}, 3 \mathrm{~s}$ and $3 \mathrm{p}$ core-level photoemission and satellite structures for Mn model compounds. Charge-transfer from the ligand state to the $3 \mathrm{~d}$ metal state is observed and is distinguished by prominent shake-up satellites. We also observe that the Mn 3s multiplet splitting becomes smaller as the Mn oxidation state increases, and that $3 \mathrm{~s}-3 \mathrm{~d}$ electron correlation reduces the branching ratio of the ${ }^{7} \mathrm{~S}:{ }^{5} \mathrm{~S}$ states in the Mn 3s spectra. In addition, as the ligand electronegativity decreases, the spin state purity is lost in the $3 \mathrm{~s}$ spectra as evidenced by peak broadening. Our results are best understood in terms of the configuration-interaction (CI) model including intrashell electron correlation, charge-transfer and final-state screening.
\end{abstract}




\section{INTRODUCTION}

Photoemission studies on transition metal compounds reveal core-level multiplet structures that are best understood in terms of configuration-interaction (CI) calculations including intrashell electron correlation, charge-transfer and final-state screening. ${ }^{1-11}$ In addition, these multiplet structures are also strongly influenced by covalency and ligand coordination. ${ }^{12,13}$

The neutral $\mathrm{Mn}$ atom has a $2 \mathrm{p}^{6} 3 \mathrm{~s}^{2} 3 \mathrm{p}^{6} 3 \mathrm{~d}^{6}$ configuration and a high-spin $\left[3 \mathrm{~d}^{5} 4 \mathrm{~s}^{2}\right]$ configuration. The (empty) $4 \mathrm{~s}$ band lies 2 to $4 \mathrm{eV}$ above the top of the $3 \mathrm{~d}^{\mathrm{N}}$ band, depending on the ion. Transitions are allowed between the initial state $2 p^{6} 3 s^{2} 3 p^{6} 3 d^{N}(N=$ 3,4,5 for $\mathrm{Mn}^{+4}, \mathrm{Mn}^{+3}, \mathrm{Mn}^{+2}$, respectively) and a series of final states $\left(2 \mathrm{p}^{5} 3 \mathrm{~d}^{\mathrm{N}+1}\right)$. Models for satellite structures in the $2 \mathrm{p}$ core-level spectra include the shakeup of a valence electron accompanying the photoionization process due to a charge-transfer mechanism from the ligand state to the $3 \mathrm{~d}$ metal state. ${ }^{6}$ For mixing or hybridization of the metal $\mathrm{d}$ states with the ligand $p$ states (valence electrons) to occur, the charge transfer states ( $\mathrm{d}^{\mathrm{N}+1}$ L) should have the same symmetry as the initial $\mathrm{d}^{\mathrm{N}}$ state. The charge-transfer energy is defined as the energy required to transfer one electron from the ligand $2 p$ states to the metal 3d states and depends strongly on the ligand electronegativity - the higher the electronegativity, the larger the charge-transfer energy. Since the $d$-d Coulomb interaction energy and the core hole-d-electron Coulomb attraction energy are primarily 
determined by atomic parameters and, thus independent of ligands, it follows that the largest influence on satellite structure would be due to charge-transfer.

It has been shown that for Mn dihalides, the outer Mn 3s core-level final state configuration can be either $\underline{3 s} 3 \mathrm{~d}^{5}$ or $\underline{3} \underline{3} 3 \mathrm{~d}^{6} \underline{\mathrm{L}}$ depending on final state screening effects due to the ligand ( $\underline{3 s}$ and $\underline{L}$ indicate that there is one electron missing in the Mn $3 \mathrm{~s}$ and the ligand valence state, respectively). Also, the 3 s final state has ${ }^{7} \mathrm{~S}$ and ${ }^{5} \mathrm{~S}$ symmetry, e.g. the $\mathrm{Mn}^{2+}$ initial state $\left(3 s^{2} 3 \mathrm{p}^{6} 3 \mathrm{~d}^{5}\right)^{6} \mathrm{~S}$ has two possible final states, $\left(3 s^{1} 3 p^{6} 3 d^{5}\right)^{7} \mathrm{~S}$ or $\left(3 s^{1} 3 p^{6} 3 d^{5}\right)^{5} S$. In the ${ }^{7} S$ state, the remaining 3 s electron is well correlated with $3 d$ electrons of parallel spin, while in the ${ }^{5} \mathrm{~S}$ state the two spins are antiparallel. This electron correlation reduces the branching ratio of the ${ }^{7} \mathrm{~S}:{ }^{5} \mathrm{~S}$ states. In addition, as the ligand electronegativity decreases, charge-transfer satellites become important and the spin state purity is lost in the $3 \mathrm{~s}$ spectra. The spectra become representative of mixed unscreened $\left(3 \mathrm{~d}^{\mathrm{N}}\right)$ and locally screened $\left(3 \mathrm{~d}^{\mathrm{N}+1}\right)$ final states. Thus, we see that the $3 \mathrm{~s}$ core-level is polarized by the $3 \mathrm{~d}^{5}$ shell.

This paper presents the results of a systematic study of the $2 \mathrm{p}, 3 \mathrm{~s}$ and $3 \mathrm{p}$ corelevel photoemission, and satellite structures for Mn model compounds. Core-level satellite structure and outer core-level multiplet splitting were characterized as a function of ligand electronegativity. Interpretation of the $2 \mathrm{p}, 3 \mathrm{p}$ and $3 \mathrm{~s}$ spectra is consistent with the configuration-interaction $(\mathrm{Cl})$ model including intrashell electron correlation, chargetransfer and final-state screening. 


\section{EXPERIMENTAL}

The model compounds $\mathrm{MnO}, \mathrm{Mn}_{2} \mathrm{O}_{3}, \mathrm{Mn}_{3} \mathrm{O}_{4}, \mathrm{MnO}_{2}, \mathrm{MnPO}_{4}$, $\mathrm{Mn}_{5}\left(\mathrm{PO}_{4}\right)_{2}\left[\mathrm{PO}_{3}(\mathrm{OH})\right]_{2} \bullet 4 \mathrm{H}_{2} \mathrm{O}$ (Alfa Aesar), MnS (Aldrich), $\mathrm{MnSO}_{4} \cdot \mathrm{H}_{2} \mathrm{O}$ (Mallinckrodt), $\mathrm{Mn}\left(\mathrm{OCH}_{3}\right)_{2}$ and $\mathrm{Mn}\left(\mathrm{C}_{5} \mathrm{H}_{7} \mathrm{O}_{2}\right)_{3}$ (Aldrich) were used as received and pressed into In foil for analysis. For these ionic and covalent model compounds, $\mathrm{Mn}$ is either in tetrahedral or octahedral coordination. Table I summarizes the oxidation states and stereochemistry of the $\mathrm{Mn}$ model compounds. It should be noted that ligand electronegativity decreases from $\mathrm{O}^{2-}$ to $\mathrm{SO}_{4}{ }^{2-}$ to $\mathrm{S}^{2-}$ to $\mathrm{PO}_{4}{ }^{3-}$. The $\left(\mathrm{OCH}_{3}\right)^{-}$and $\left(\mathrm{C}_{5} \mathrm{H}_{7} \mathrm{O}_{2}\right)^{-}$ligands are covalently bound to the Mn.

ESCA experiments were performed on a Physical Electronics 5400 ESCA system using $\mathrm{Mg} \mathrm{K} \alpha$ radiation (1253.6 eV) and a hemispherical analyzer pass energy of 17.90 $\mathrm{eV}$ giving an overall energy resolution of $1.1 \mathrm{eV}$. Binding energies were referenced to the C 1s photoelectron line arising from adventitious carbon at $284.6 \mathrm{eV}$.

\section{RESULTS AND DISCUSSION}

Figure 1 presents the Mn 2p spectra for the set of model compounds. The binding energy positions for the $\mathrm{Mn} 2 \mathrm{p}_{3 / 2,1 / 2}$ spin-orbit components range between $641-643 \mathrm{eV}$ and $654-655 \mathrm{eV}$, respectively, in agreement with literature values ${ }^{14-17}$ and are summarized in Table II. The full width half-maximum (FWHM) of the $\mathrm{Mn} 2 \mathrm{p}_{32}$ peak is $2.5-3.4 \mathrm{eV}$ for these powdered samples. One distinguishing feature of all the $\mathrm{Mn}^{+2}$ species in the 
phosphates and sulfate is the prominent shake-up satellite about $5 \mathrm{eV}$ higher than the $\mathrm{Mn}$ $2 \mathrm{p}_{3 / 2}$ peak and is due to charge-transfer. ${ }^{6}$ In addition, this satellite-main peak splitting varies approximately as the ligand valence binding energy.

The Auger parameters are also listed in Table I. For the oxide standards, the Auger parameter becomes less negative with increasing oxidation. The Auger parameter for phosphates and sulfates are clustered around $-31 \mathrm{eV}$. Figure 2 shows a plot of the $\mathrm{Mn}$ $2 p_{3 / 2}$ binding energy versus the Mn LMM Auger kinetic energy. The Auger parameter plots are useful for further separation of the Mn chemical states and clearly show the phosphates and sulfates clustered in the left bottom corner between $\alpha=-30.6$ and -31.6 , away from the oxides.

Understanding the Mn $2 p$ final states $\left(2 p^{5} 3 d^{N+1}\right)$ requires knowledge of the $3 d$ core-level in the valence band. The $3 \mathrm{~d}$ level in an octahedral coordination (e.g. $\mathrm{Mn}$ oxides) is split into higher energy doubly degenerate $\left(e_{g}\right)$ and lower energy triply degenerate $\left(t_{2 g}\right)$ levels by the crystal field. In contrast, the $3 \mathrm{~d}$ level in a tetrahedral coordination (e.g. $\mathrm{MnSO}_{4}$ ) is split into higher energy triply degenerate $\left(t_{28}\right)$ and lower energy doubly degenerate $\left(e_{g}\right)$ levels by the crystal field. The energy difference between the two levels is determined by the strength of the crystal potential and is larger for the octahedral case. If the interaction between the $2 \mathrm{p}$ core hole and the correlated $3 \mathrm{~d}$ valence electrons is sufficiently strong, satellites accompanying the main lines are present in the photoemission spectra. As stated, we observe this satellite feature to varying degrees for 
the phosphates and sulfates having tetrahedral coordination. In addition, since the P $3 p$ and $S 3 p$ states in the valence band share the same principal quantum number as the $\mathrm{Mn}$ $3 \mathrm{~d}$ states, their overlap will be the largest. The oxides with octahedral coordination (O 2p states in the valence band) do not exhibit this satellite feature.

Figure 3 shows the entire Mn 3p and 3s spectral region for the model compounds. As previously stated, the excitation energy was $1253.6 \mathrm{eV}$, and thus the positions and relative intensities of the $\mathrm{Mn} 3 \mathrm{~s}$ and $\mathrm{Mn} 3 \mathrm{p}$ multiplets can be considered to be in the sudden limit approximation ${ }^{2,3}$ with little coupling between the ion and the photoelectron. The figure clearly shows a chemical shift of the $\mathrm{Mn} 3 \mathrm{p}_{3 / 2,12}$ spin-orbit pair associated with

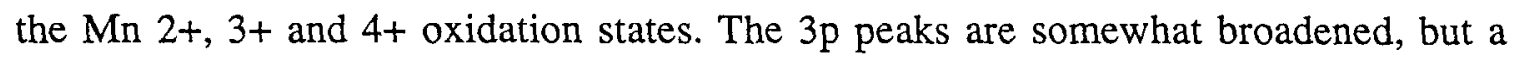
direct correspondence can be made between observed features in these spectra and those in the literature. ${ }^{10,11}$ Specifically, the main $3 p$ line represents the ${ }^{7} \mathrm{P}$ ionic final state and the higher binding energy shoulder represents the spin-orbit component ${ }^{5} \mathrm{P}(1)$. The spectrum for $\mathrm{Mn}\left(\mathrm{OCH}_{3}\right)_{2}$ has a stronger than usual feature $6.6 \mathrm{eV}$ from the main peak representative of ${ }^{5} \mathrm{P}(2)$. Also, the broad feature $\approx 20 \mathrm{eV}$ from the main $3 \mathrm{p}$ peak in all the spectra is attributed to an energy-loss peak.

Figure 4 shows the expanded Mn 3s region for the model compounds. The binding energy positions for the $\mathrm{Mn} 3 \mathrm{~s}^{7} \mathrm{~S}$ and ${ }^{5} \mathrm{~S}$ multiplet components range between $81-83 \mathrm{eV}$ and $87-89 \mathrm{eV}$, respectively, and are summarized in Table III. Figure 5 graphically summarizes the Mn oxidation state versus Mn 3 s multiplet splitting for the 
Mn model compounds. Note that the Mn 3s multiplet splitting ( $\Delta \mathrm{Mn} 3 \mathrm{~s}$ ) becomes smaller as the Mn oxidation state increases, consistent with published data, except for the $\mathrm{MnPO}_{4}$, which is anomalously high. The polarization of the $-\mathrm{PO}_{4}$ ligand may account for this anomalous behavior since it would draw more charge from the $\mathrm{Mn}$ atom. Also note that the ${ }^{7} \mathrm{~S}$ and ${ }^{5} \mathrm{~S}$ multiplet components shift considerably since it involves the binding energy of a ligand valence electron. As previously stated, as the ligand electronegativity decreases, charge-transfer satellites become important and the spin state purity is lost in the $3 \mathrm{~s}$ spectra. Broadening of the $3 \mathrm{~s}$ peaks would result as we observe for the $\mathrm{PO}_{4}^{3-}$ ligand having the lowest electronegativity. The covalently bound ligands $\left(\mathrm{OCH}_{3}\right)^{-}$and $\left(\mathrm{C}_{5} \mathrm{H}_{7} \mathrm{O}_{2}\right)^{-}$ also exhibit broader than usual 3s peaks. The multiplet splitting for these ligands are quite different indicating their polarizations are different. As in the case of the $-\mathrm{PO}_{4}$ ligand, the multiplet splitting for the $-(\mathrm{acac})_{3}$ ligand is high. The strong polarization of this ligand withdraws mobile $\pi$ electrons from the $\mathrm{Mn}$ atom thus affecting the multiplet splitting.

\section{CONCLUSIONS}

We have presented the results of a systematic study of the Mn $2 \mathrm{p}$ core-level satellite structure and the $\mathrm{Mn} 3 \mathrm{~s}$ and $3 \mathrm{p}$ outer core-level multiplet splitting of Mn model compounds as a function of ligand electronegativity. The satellite structure observed in the Mn 2p spectra is clearly associated with ligand $2 p$ to $M n 3 d$ charge-transfer based on sound theoretical arguments and previous experimental work. Also, the Mn 3s multiplet 
splitting became smaller as the Mn oxidation state increased. The atomic calculations of Bagus, Freeman and Sasaki ${ }^{2}$ including configuration interaction (CI) and correlation in the final states best describes the observed multiplet splitting. The interpretation of the $2 p$ and $3 \mathrm{~s}$ spectra for these model compounds are thus consistent and complementary.

\section{Acknowledgments}

This work was performed under the auspices of the U.S. Department of Energy under Contract W-7405-ENG-48 at LLNL. 


\section{References}

1. S.P. Kowalczyk, L. Ley, R.A. Pollack, F.R. McFeely and D.A. Shirley, Phys. Rev. B7, 4009 (1973).

2. P.S. Bagus, A.J. Freeman and F. Sasaki, Phys. Rev. Lett. 30, 850 (1973).

3. C.S. Fadley, in Electron Spectroscopy: Theory, Techniques, and Applications, edited by C.R. Brundle and A.D. Baker (Academic, London, 1978) Vol. II, Chap. 1.

4. G. van der Laan, C. Westra, C. Haas and G.A. Sawatzky, Phys. Rev. B23, 4369 (1981).

5. J. Zaanen, C. Westra and G.A. Sawatzky, Phys. Rev. B33, 8060 (1986).

6. Jaehoon Park, Seungoh Ryu, Moon-sup Han and S.-J. Oh, Phys. Rev. B37, 10867 (1988).

7. Geunseop Lee and S.-J. Oh, Phys. Rev. B43, 14674 (1991).

8. S.-J. Oh, Gey-Hong Gweon and Je-Geun Park, Phys. Rev. Lett. 68, 2850 (1992).

9. Gey-Hong Gweon, Je-Geun Park and S.-J. Oh, Phys. Rev. B48, 7825 (1993).

10.B. Hermsmeier, C.S. Fadley, M.O. Krause, J. Jimenez-Mier, P. Gerard and S.T. Manson, Phys. Rev. Lett. 61, 2592 (1988).

11. B. Hermsmeier, C.S. Fadley, B. Sinkovic, M.O. Krause, J. Jimenez-Mier, P. Gerard, T.A. Carlson, S.T. Manson and S.K. Bhattacharya, Phys. Rev. B48, 12425 (1993).

12. M. Fujiwara, T. Matsushita and S. Ikeda, J. Electron Spectroscopy Rel. Phenom. 74, 201 (1995). 
13. B.W. Veal, D.E. Ellis and D.J. Lam, Phys. Rev. B32, 5391 (1985).

14. J. F. Moulder, W. F. Stickle, P. E. Sobol and K. D. Bomben, Handbook of X-Ray Photoelectron Spectroscopy, Perkin-Elmer Corporation, Physical Electronics Division, Eden Prairie, MN 55344 (1992).

15. B. R. Strohmeier and D. M. Hercules, J. Phys. Chem. 88, 4922 (1984).

16. A. Aoki, Japan J. Appl. Phys. 15(2), 305 (1976).

17. J. C. Carver, G. K. Schwietzer and T. A. Carlson, J. Chem. Phys. 57(2), 973 (1972). 


\section{Figure Captions}

Figure 1. High-resolution XPS spectra of Mn 2p core levels for the Mn model compounds.

Figure 2. Mn 2p Auger parameter diagram further separating manganese chemical states.

Figure 3. High-resolution XPS spectra of Mn 3p and 3s core levels for the Mn model compounds.

Figure 4. Expanded Mn 3s core level spectra for the Mn model compounds.

Figure 5. Mn oxidation state versus Mn 3s multiplet separation for the Mn model compounds. 
Table I. Oxidation States and Stereochemistry of Mn Model Compounds.

\begin{tabular}{|c|c|c|c|c|}
\hline Compound & $\begin{array}{l}\text { Oxidation } \\
\text { State } \\
\end{array}$ & $\begin{array}{c}\text { Coordination } \\
\text { Number }\end{array}$ & Geometry & Crystal System \\
\hline $\mathrm{MnO}$ & $\mathrm{Mn}^{2+}$ & 6 & octahedral & isometric \\
\hline $\mathrm{Mn}_{2} \mathrm{O}_{3}$ & $\mathrm{Mn}^{3+}$ & 6 & octahedral & monoclinic \\
\hline $\mathrm{Mn}_{3} \mathrm{O}_{4}$ & $\begin{array}{l}\mathrm{Mn}^{2+} \\
\mathrm{Mn}^{3+}\end{array}$ & $\begin{array}{l}4 \\
6 \\
\end{array}$ & $\begin{array}{l}\text { tetrahedral } \\
\text { octahedral }\end{array}$ & isometric \\
\hline $\mathrm{MnO}_{2}$ & $\mathrm{Mn}^{4+}$ & 6 & octahedral & tetragonal \\
\hline $\mathrm{MnPO}_{4}$ & $\mathrm{Mn}^{3+}$ & 6 & octahedral & $\begin{array}{l}\text { isometric } \\
\text { tetragonal }\end{array}$ \\
\hline Hureaulite $^{\mathrm{a}}$ & $\mathrm{Mn}^{2+}$ & 4 & tetrahedral & \\
\hline $\mathrm{MnS}$ & $\mathrm{Mn}^{2+}$ & 4 & tetrahedral & isometric \\
\hline $\mathrm{MnSO}_{4}$ & $\mathrm{Mn}^{2+}$ & 4 & tetrahedral & monoclinic \\
\hline $\mathrm{Mn}\left(\mathrm{OCH}_{3}\right)_{2}$ & $\mathrm{Mn}^{2+}$ & 4 & tetrahedral & \\
\hline $\begin{array}{c}\operatorname{Mn}(2,4) \\
\text { Pentanedione }^{\mathrm{b}}\end{array}$ & $\mathrm{Mn}^{3+}$ & 6 & octahedral & \\
\hline
\end{tabular}

a) $\mathrm{Mn}_{5}\left(\mathrm{PO}_{4}\right)_{2}\left[\mathrm{PO}_{3}(\mathrm{OH})\right]_{2} \bullet 4 \mathrm{H}_{2} \mathrm{O}$.

b) $\mathrm{Mn}\left(\mathrm{C}_{5} \mathrm{H}_{7} \mathrm{O}_{2}\right)_{3}$ or $\mathrm{Mn}(\mathrm{acac})_{3}$ 
Table II. Values of Binding Energies (in eV) for Manganese Model Compounds.

\begin{tabular}{|c|c|c|c|c|c|c|c|}
\hline Sample & $\operatorname{Mn} 2 p_{3 / 2}$ & FWHM $^{\mathrm{a}}$ & Mn $\mathrm{LMM}^{\mathrm{d}}$ & $\alpha^{e}$ & $01 \mathrm{~s}$ & $S 2 p$ & P $2 p$ \\
\hline $\mathrm{MnO}$ & 640.9 & 3.2 & 582.9 & -29.8 & 530.0 & - & - \\
\hline $\mathrm{Mn}_{3} \mathrm{O}_{4}$ & 641.0 & 3.2 & 583.4 & -29.2 & 529.9 & - & - \\
\hline $\mathrm{Mn}_{2} \mathrm{O}_{3}$ & 641.2 & 3.0 & 583.4 & -29.0 & 529.8 & - & - \\
\hline $\mathrm{MnO}_{2}$ & 641.9 & 2.5 & 583.6 & -28.1 & 529.5 & - & - \\
\hline $\mathrm{MnPO}_{4}$ & 641.9 & 3.3 & 581.0 & -30.7 & 531.8 & - & 134.0 \\
\hline Hureaulite $^{b}$ & 641.6 & 3.4 & 581.2 & -30.8 & $\begin{array}{l}531.5 \\
532.8\end{array}$ & - & 133.6 \\
\hline $\mathrm{MnSO}_{4}$ & 641.9 & 3.3 & 581.1 & -30.6 & 532.2 & 168.8 & - \\
\hline $\mathrm{MnS}$ & 640.5 & 3.2 & 584.3 & -28.8 & - & 161.7 & - \\
\hline $\mathrm{Mn}\left(\mathrm{OCH}_{3}\right)_{2}$ & 642.3 & 3.0 & - & - & $\begin{array}{l}529.5 \\
533.9\end{array}$ & - & - \\
\hline $\begin{array}{c}\operatorname{Mn}(2,4) \\
\text { Pentanedione }\end{array}$ & 641.2 & 3.3 & - & - & 531.2 & - & - \\
\hline
\end{tabular}

a) Full width half-maximum of $\mathrm{Mn} 2 \mathrm{p}_{3 / 2}$ peak in $\mathrm{eV}$.

b) $\mathrm{Mn}_{5}\left(\mathrm{PO}_{4}\right)_{2}\left[\mathrm{PO}_{3}(\mathrm{OH})\right]_{2} \bullet 4 \mathrm{H}_{2} \mathrm{O}$.

c) $\mathrm{Mn}\left(\mathrm{C}_{5} \mathrm{H}_{7} \mathrm{O}_{2}\right)_{3}$ or $\mathrm{Mn}(\mathrm{acac})_{3}$

d) Kinetic energy of $M n L_{3} M_{2,3} M_{4,5}$ Auger peak.

e) Auger parameter, $\alpha=\mathrm{BE}+\mathrm{KE}-1253.6 \mathrm{eV}$. 
Table III. Summary of the Mn 3s Photoelectron Results for Manganese Model

\section{Compounds.}

\begin{tabular}{|c|c|c|c|c|c|c|}
\hline \multirow[t]{2}{*}{ Sample } & \multicolumn{2}{|c|}{$\mathrm{Mn} 3 \mathrm{~s}(\mathrm{eV})$} & \multicolumn{2}{|c|}{$\mathrm{FWHM}^{\mathrm{a}}$} & \multirow{2}{*}{$\begin{array}{c}\Delta \mathrm{Mn} 3 \mathrm{~s} \\
(\mathrm{eV})\end{array}$} & \multirow{2}{*}{$\begin{array}{c}\text { Mn 3s } \\
\text { Branching } \\
\text { Ratio }^{\mathrm{b}} \\
\end{array}$} \\
\hline & ${ }^{7} \mathrm{~S}$ & ${ }^{5} \mathrm{~S}$ & ${ }^{7} S$ & ${ }^{5} S$ & & \\
\hline $\mathrm{MnO}$ & 81.4 & 87.0 & 3.2 & 3.4 & 5.6 & 1.5 \\
\hline $\mathrm{Mn}_{3} \mathrm{O}_{4}$ & 81.6 & 87.2 & 3.7 & 3.7 & 5.6 & 1.5 \\
\hline $\mathrm{Mn}_{2} \mathrm{O}_{3}$ & 82.1 & 87.5 & 3.2 & 3.8 & 5.4 & 1.4 \\
\hline $\mathrm{MnO}_{2}$ & 83.0 & 87.5 & 3.4 & 3.8 & 4.5 & 1.4 \\
\hline $\mathrm{MnPO}_{4}$ & 82.6 & 88.5 & 5.1 & 3.8 & 5.9 & 1.8 \\
\hline Hureaulite $^{\mathrm{c}}$ & 81.7 & 87.9 & 3.3 & 3.3 & 6.2 & 1.7 \\
\hline $\mathrm{MnSO}_{4}$ & 82.5 & 88.7 & 3.3 & 3.5 & 6.2 & 1.7 \\
\hline $\mathrm{MnS}$ & 81.0 & 86.9 & 3.5 & 5.5 & 5.9 & 1.1 \\
\hline $\mathrm{Mn}\left(\mathrm{OCH}_{3}\right)_{2}$ & 82.8 & 88.3 & 3.3 & 4.2 & 5.4 & 1.5 \\
\hline $\begin{array}{c}\operatorname{Mn}(2,4) \\
\text { Pentanedione }^{d}\end{array}$ & 82.6 & 88.7 & 4.0 & 4.2 & 6.1 & 1.4 \\
\hline
\end{tabular}

a) Full width half-maximum of $\mathrm{Mn} 3 \mathrm{~s}$ peaks in $\mathrm{eV}$.

b) The branching ratio of the $\mathrm{Mn} 3 \mathrm{~s}$ peaks are based on peak areas, i.e. area ratio of the ${ }^{7} \mathrm{~S}:{ }^{5} \mathrm{~S}$ states.

c) $\mathrm{Mn}_{5}\left(\mathrm{PO}_{4}\right)_{2}\left[\mathrm{PO}_{3}(\mathrm{OH})\right]_{2} \cdot 4 \mathrm{H}_{2} \mathrm{O}$.

d) $\mathrm{Mn}\left(\mathrm{C}_{5} \mathrm{H}_{7} \mathrm{O}_{2}\right)_{3}$ or $\mathrm{Mn}(\mathrm{acac})_{3}$ 


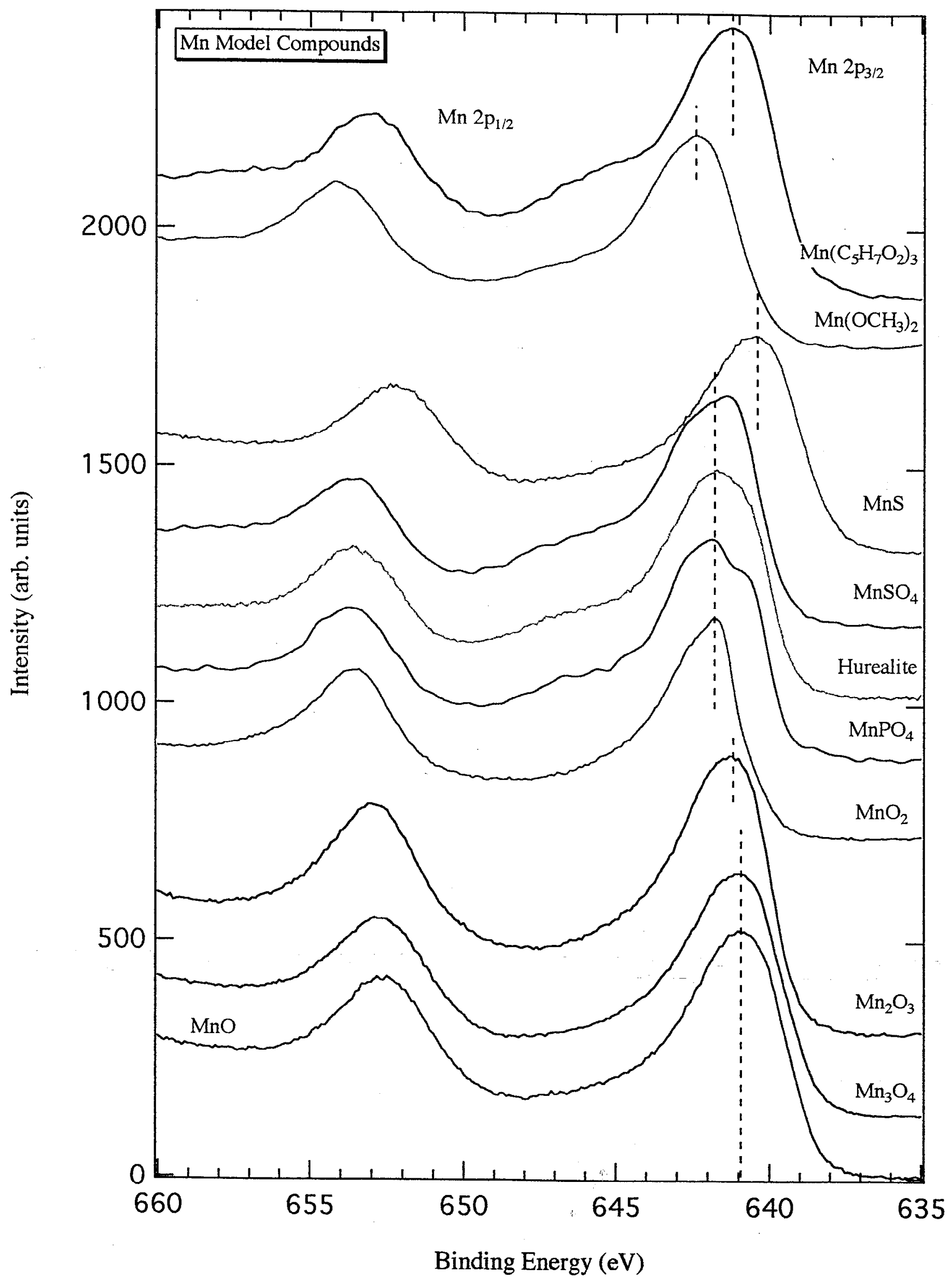




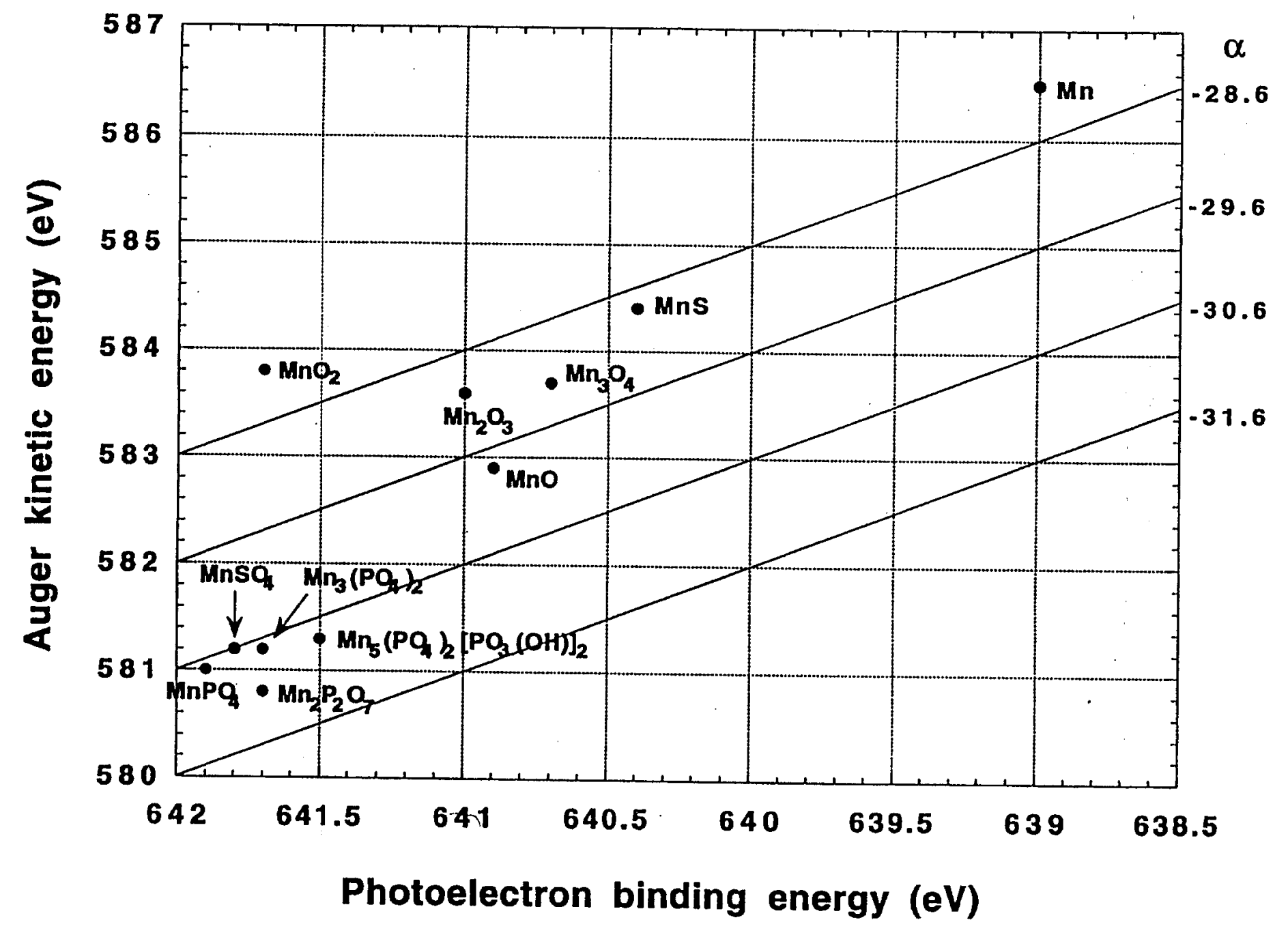




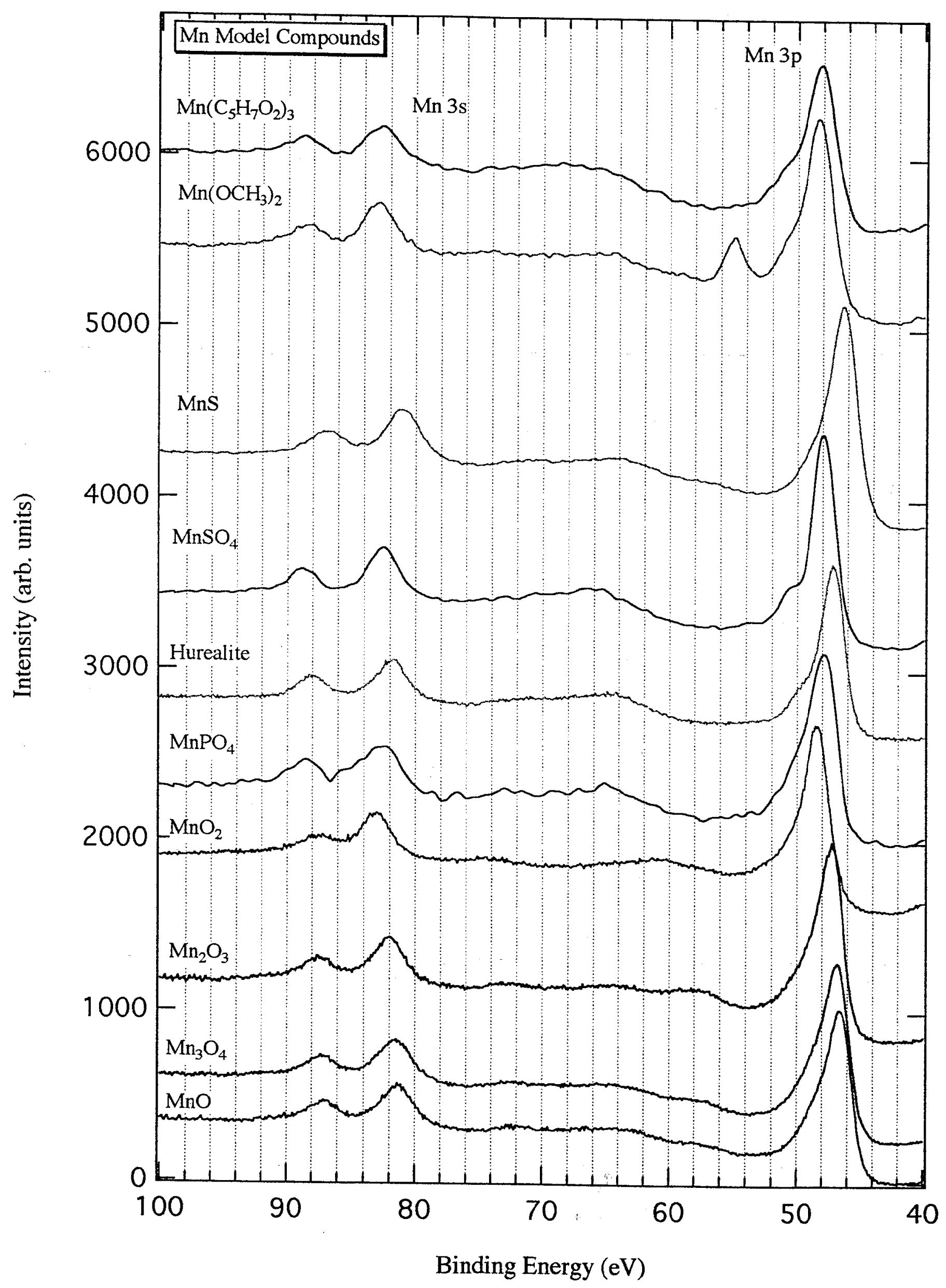




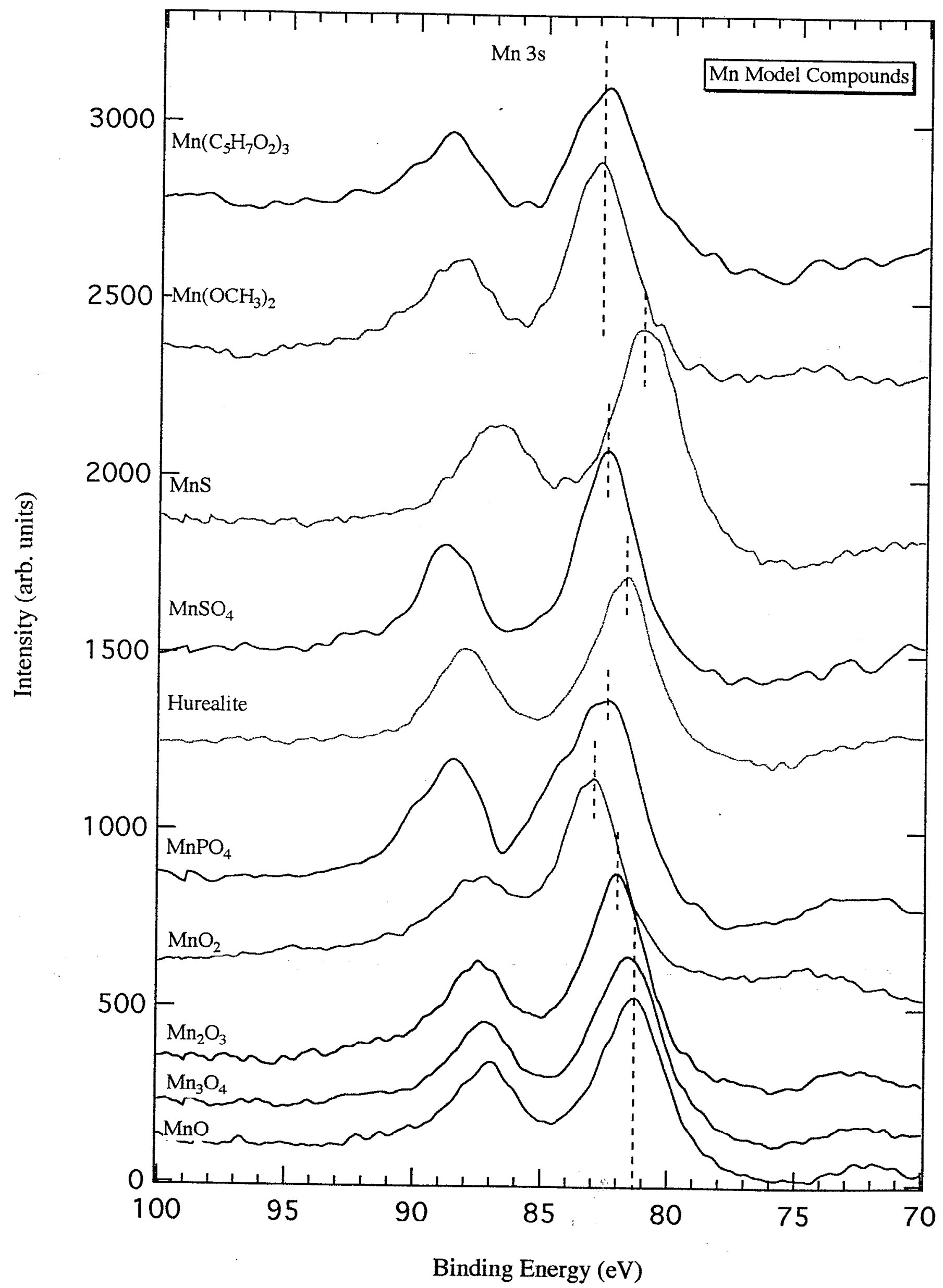




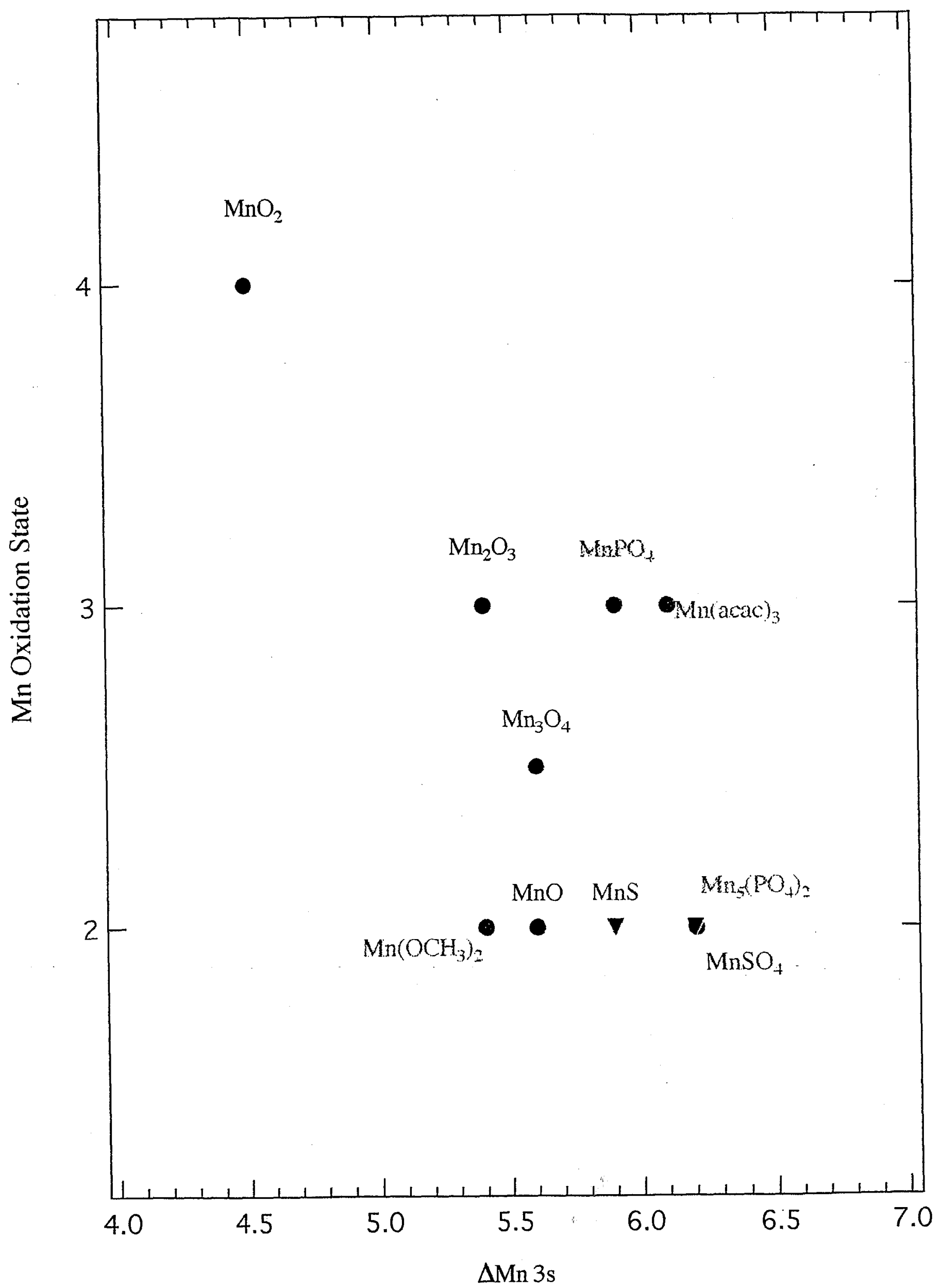

